Journal of Applied Pharmaceutical Science Vol. 5 (10), pp. 085-090, October, 2015

Available online at http://www.japsonline.com

DOI: $10.7324 / \mathrm{JAPS} .2015 .501015$

ISSN 2231-3354 (cc) BY-NC-SA

\title{
Chitosan nanoparticles loaded antibiotics as drug delivery biomaterial
}

\author{
Hassan M. Ibrahim*, Manal K. El-Bisi, Ghada M. Taha, Ekhlas A. El-Alfy \\ National Research Center, Textile Research Division, Dokki, Cairo, Egypt.
}

\section{ARTICLE INFO \\ Article history: \\ Received on: 18/07/2015 \\ Revised on: 14/08/2015 \\ Accepted on: 02/09/2015 \\ Available online: 28/10/2015}

\section{Key words:}

Chitosan nanoparticles,

Ciprofloxacin,

Chlortetracycline

hydrochloride, Gentamycin

sulfate Ionotropic gelation,

Antibacterial activity and

Drug Delivery.

\begin{abstract}
Herein we describe the preparation, characterization and utilization of chitosan nanoparticles for the intracellular delivery of the poorly cell-penetrating antibiotic e.g. Ciprofloxacin, Chlortetracycline hydrochloride and Gentamycin sulfate to improve their treatment of bacterial infections. Chitosan nanoparticles were prepared via the ionic gelation of chitosan with tri polyphosphate anions. Several parameters were studied to optimize the particle size of chitosan nanoparticles, here we select the concentration of chitosan and the concentrations of sodium tri poly phosphate (TPP) as optimizing parameters and the other factors stay constant such as $\mathrm{pH}$ of solution and ultrasonication time. Chitosan nanoparticles formed characterized by using FT-IR and transmission electron microscope (TEM). Results show that chitosan nanoparticles and its loaded antibiotics kill and inhibits the growth of gram (+) and gram (-) bacteria tested due to nanoparticles structures, and the antibacterial activity increased with increasing the anti biotic content.
\end{abstract}

\section{INTRODUCTION}

The purpose of this study was to explore the possible improvement of antimicrobial treatment by its incorporation into chitosan-based nanoparticles. Limited cellular penetration reduces the effectiveness of many antimicrobial treatments; and overcome the side effects of selected antibiotecs such as Ciprofloxacin, Chlortetracycline hydrochloride and Gentamycin sulfate to improve their treatment of bacterial infections(Zaki and Hafez, 2012). Chitosan is a copolymer composed of N-acetyl glucosamine and glucosamine units (Chattopadhyay and Inamdar, 2013).It has been used as antibacterial and anti-fungal substance (Benhabiles et al., 2012; Lahmer et al., 2012; CruzRomero et al., 2013; Limam et al., 2013). There are several mechanisms that explain the antibacterial activity of chitosan, the most common one assume that chitosan binds to the negatively charged bacterial surface disrupting the cell membrane and altering its permeability. This allows materials to leak out of the bacterial cells resulting in cell death (Abou-Zeid et al., 2011).

\footnotetext{
* Corresponding Author

Hassan M. Ibrahim, National Research Center, Textile Research

Division, Dokki, Cairo, Egypt.Email: hmaibrahim@gmail.com
}

Chitosan has antibacterial activity only in an acidic medium because of its poor solubility above $\mathrm{pH}$ 6.5.There are several factors affect the antibacterial activity of chitosan such as chitin type, degree of polymerization, molecular weight solvent some physciochemical properties and $\mathrm{pH}$ of the solution ( $\mathrm{Li}$ et al., 2002, Dash et al., 2011; Jimtaisong and Saewan, 2014; El-Sherbiny and El-Baz, 2015). Chitosan exhibits higher antibacterial activity against Gram-positive bacteria than Gram-negative bacteria, this is due to their different cell walls. In Gram-positive bacterium, its cell wall is fully composed of peptide polyglycogen. The peptidoglycan layer is composed of networks with plenty of pores, which allow foreign molecules to come into the cell without difficulty. ButIn Gram-negative bacterium, the cell wall of which is made up of a thin membrane of peptide polyglycogen and an outer membrane constituted of lipopolysaccharide, lipoprotein and phospholipids. Because of the bilayer structure, the outer membrane is a potential barrier against foreign molecules (Jia and Xu, 2001; No et al., 2002; Abou-Zeid et al., 2011; Lu et al., 2014). Chitosan is a mucoadhesive polymer that is able to open tight junctions and allow the paracellular transport of molecules across mucosal delivery of vaccines (Van der Lubben et al., 2001; Sawaengsak et al., 2014; Del Guidice and Baudner, 2015). 
Chitosan nanoparticles exhibit higher antibacterial activity than chitosan based on the special character of the nanoparticles. The negatively charged surface of the bacterial cell is the target site of the polycation. Therefore, the polycationic chitosan nanoparticles with higher surface charge density interact with the bacteria to a greater degree than chitosan itself. Chitosan nano-particles provide higher affinity with bacteria cells for a quantum-size effect, due to the larger surface area of the chitosan nanoparticles, which could be tightly adsorbed onto the surface of the bacteria cells to disrupt the membrane, which would lead to the leakage of intracellular components, thus killing the bacteria cells(Avadi et al., 2004, Abdel-Fattah et al., 2014).

Chitosan nanoparticles has been used as drug carriers and gene carrier to enhance their transfer efficiency in the cells as reported in several studies(Chopra et al., 2014, Csaba and Alonso, 2014, Garrait et al., 2014, Liu et al., 2014, Lu et al., 2014, Nascimento et al., 2014, Ragelle et al., 2014).

Chitosan nanoparticles were used as drug delivery carriers due to it offers many advantages. First, chitosan is safe material as it has biocompatible and biodegradable properties. Second, it is water-soluble polymers which is an ideal property for drug delivery carriers, therefore, simple and mild preparation methods can be applied. This renders chitosan nanoparticle are suitable for a broad category of drugs including macromolecules and labile drugs. Third, chitosan is available in a wide range of molecular weights and is easily chemically modified by coupling with ligands providing flexibility in formulation development. Forth, chitosan provides absorption promoting effect that prolongs the contact time between substrate and cell membrane. In addition, their nano-sized facilitates the drug uptake through the cell membrane. Together, the absorption enhancing effect and nanosized particles exhibited ability to improve drug bioavailability. Fifth, chitosan nanoparticles offer versatile routes of administration, especially non-invasive routes, i.e. per oral, nasal, and ocular mucosa, which are preferable routes administration. Furthermore, chitosan nanoparticles demonstrated to be good adjuvant for vaccine delivery (Kim et al., 2004; Liu et al., 2014; Lu et al., 2014; Nascimento et al., 2014; Ragelle et al., 2014).

An antibiotic is a drug that kills or inhibit the growth of bacteria, antibiotics are classified into four categories: antibacterial, antiviral, antifungal, and antineoplastic. Antibiotics work by a number of different actions including inhibition or regulation of cell wall synthesis, nucleic acid metabolism, and protein synthesis. The main classes of antibiotics are $\beta$-Lactams, Macrolides, Fluoroquinolones (Ciprofloxacin), Tetracyclines (tetra Chlortetracycline) and Aminoglycosides (gentamycin) (Chopra et al., 1997; Walsh, 2003; Walsh, 2003; Taubes, 2008).

The present work is aimed to prepare chitosan nanoparticles by using ionic gelation method and characterize it by using FT-IR and TEM to be used as polyloaddrug delivery of some antibiotics names, Ciprofloxacin antibiotic as ciprofloxacin HCL, Chlortetracycline hydrochloride and Gentamycin sulfate. Then evaluate their antibacterial activities.

\section{EXPERIMENTAL}

\section{Materials}

Chitosan (Alfa Aesar Company, Medium molecular weight, viscosity $1860 \mathrm{cps}$, degree of deacetylation $79.0 \%$ ), penta sodium tri poly phosphate (TPP).Sodium hydroxide (Modern Lab chemicals, Egypt), Methyl alcohol, ethyl alcohol and acetic acid (Sisco Research Laboratories, India) and all other chemicals used are analytical grade and were used without further purification Antibiotics used are: ciprofloxacin HCL, Chlortetracycline hydrochloride and Gentamycin sulfate (Memphis pharm and chemical industry).

\section{Methods \\ Preparation of chitosan nanoparticles}

Chitosan nanoparticles were prepared based on the modified ionotropic gelation with slight modification (Qi et al., 2004; Du et al., 2009; Lu et al., 2009). Briefly, Chitosan was dissolved in $1 \%(\mathrm{v} / \mathrm{v})$ acetic acid and leaving it under stirring for $24 \mathrm{~h}$. The $\mathrm{pH}$ was adjusted to $\mathrm{pH} 5.5$ with $0.01 \mathrm{~N} \mathrm{NaOH}$. TPP was dissolved separately in deionized water to final concentration of $0.1 \mathrm{mg} / \mathrm{ml}$. Then, the TPP solution was added to the chitosan solution drop wise at different TPP:chitosan ratios under vigorous magnetic stirring at room temperature. The resulting suspension was then left under ultrasonication for $45 \mathrm{~min}$.

\section{Preparation of Antibiotic-loaded chitosan nanoparticles:}

Different concentration of the antibiotic dissolved in distilled water was added to nano-chitosan solution in the same molar ratio with stirring for $20 \mathrm{~min}$. and The resulting suspension was then left under ultrasoincation for $45 \mathrm{~min}$. then finally stirring for another $20 \mathrm{~min}$., to obtain a final antibiotic concentration $(0.05$, $0.1,0.15,0.2,0.5 \% \mathrm{gm} / \mathrm{ml})(\mathrm{Jain}$ and Banerjee, 2008, Du et al., 2009).

\section{Characterization of chitosan nanoparticle and its loaded}

The FTIR spectra of the samples were recorded by using an FT- IR spectrophotometer (Nexus 670, Nicolet, USA) in the region of 4000-400 cm-1 with spectra resolution of $4 \mathrm{~cm}^{-1}$.

Shape and size of chitosan Nanoparticle was investigated using JEOL, TEM-Speciments for TEM measurements were prepared by placing a drop of colloidal solution on 400 mesh copper grid coated by an amorphous carbon film and evaporating the solvent in air at room temperature. The average diameter of chitosan nanoparticle was determined from diameter of 100 nanoparticle found in several arbitrarily chosen are in enlarged microphotographs.

\section{Evaluation of Antibacterial Activity in vitro Materials}

Two bacterial strains from Bacterial Lab, Botany Department, the Faculty of women for Art, Science \& Education, Ain Shams University, Cairo, Egypt were employed. They include Staphylococcus aureus (S. aureus) as Gram-positive $(\mathrm{G}+\mathrm{ve})$ 
bacteria and Escherichia coli $($ E. coli) as gram-negative $(\mathrm{G}-\mathrm{ve})$ bacteria. $S$. aureus and $E$. coli were selected as test cells because they are the most frequent bacteria in the wound infection and represent Gram positive and Gram negative bacteria, respectively. Fresh inoculants for antibacterial assessment were prepared on nutrient broth at $37{ }^{\circ} \mathrm{C}$ for 24 hours.

\section{Test Method}

The antibacterial spectrum of chitosan, nanochitosan and their loaded antibiotic samples were determined against the test bacteria by disk diffusion method on an agar plate(Abou-Zeid et al., 2011). Briefly, $1 \mathrm{~cm}$ diameter blended film samples were cut and put into $10 \mathrm{ml}$ of nutrient agar, to which $10 \mu \mathrm{l}$ of microbe culture was inoculated, after the solidification. The plates were incubated at $37{ }^{\circ} \mathrm{C}$ for $24 \mathrm{hrs}$, after which the diameter of inhibition zone were measured and recorded.

\section{RESULT AND DISCUSSION}

\section{Preparation and Characterization of chitosan nanoparticles}

The preparation of chitosan nanoparticles is based on an ionic gelation interaction between positively charged chitosan and negatively charged tripolyphosphate at room temperature represented figure 1 . The interaction can be controlled by the charge density of TPP and chitosan, which is dependent on the $\mathrm{pH}$ of the solution and ultra sonication time.

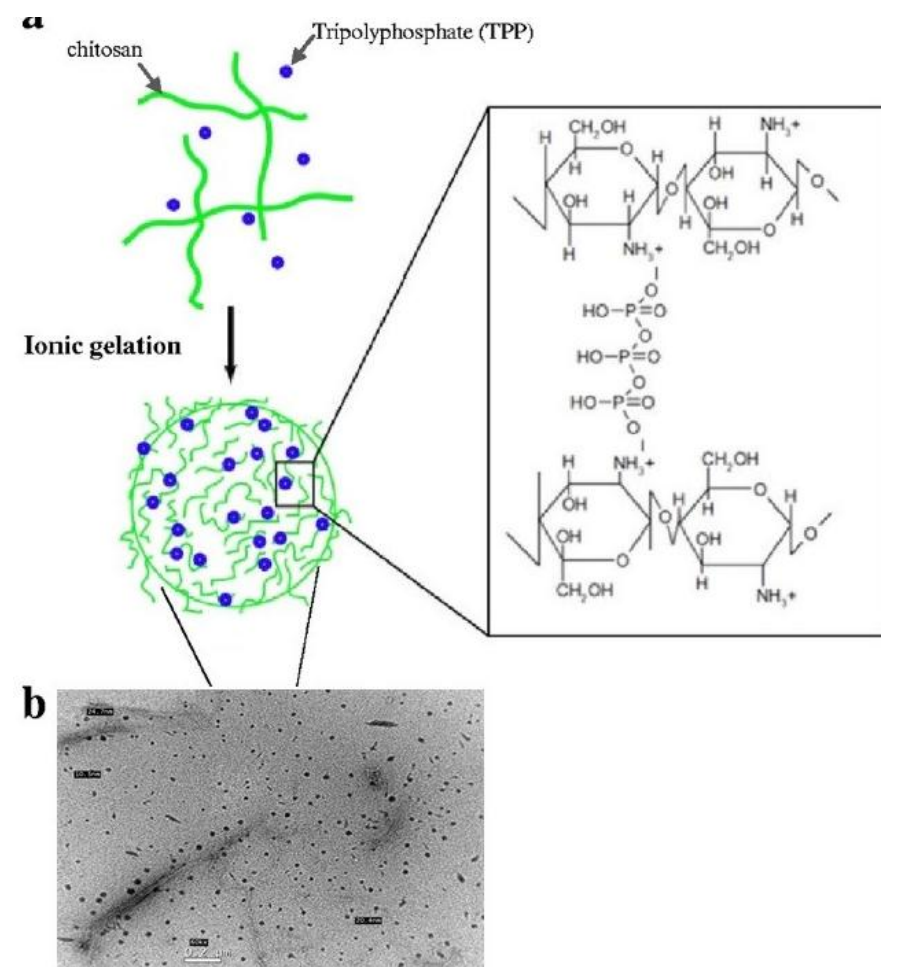

Fig. 1: Formation of the chitosan-tripolyphosphate complex byionotropic gelation. (a) Schematic illustration of the chitosan-TPPcomplex and (b) TEM image.of chitosan nanoparticles with $25 \mathrm{~nm}$ diameter.

There are many factor have effect on the size of chitosan nanoparticles: chitosan concentration, sodium tri poly phosphate concentration, $\mathrm{pH}$ of solution and ultrasonication time; herein we kept the $\mathrm{pH}$ of solution and ultrasoincation time constant at $\mathrm{pH} 5.5$ and $45 \mathrm{~min}$. respectively based on previous study $(\mathrm{Xu}$ and $\mathrm{Du}$, 2003)and changing the concentration of both chitosan and TPP.

\section{Effect of chitosan concentration on nanoparticle size}

By studying the chitosan concentration effect $(0.1,0.15$, 0.2 ) $\mathrm{g} / \mathrm{mlat}$ constant other parameter such as concentration of sodium tri polyphosphate $(0.1) \mathrm{g} / \mathrm{l}$ and $\mathrm{pH} 5.5$ and ultrasonication time 45min., It was observed that with increase in the concentration of chitosan the appearance of the solution changed from clear viscous liquid to opalescent fluid and then precipitated the solution became opalescent indicating the formation of nanochitosan with smallest nano size ranged (2-8) $\mathrm{nm}$. From figure2 is obvious that by increasing the chitosan concentration from 0.1 to $0.2 \mathrm{~g} / \mathrm{mL}$ at a constant TPP concentration $(0.1 \mathrm{~g} / \mathrm{mL})$, the size of nanoparticles decrease, nano size of particles are more favorable at the chitosan concentration of $0.2 \mathrm{~g} / \mathrm{ml}(2-8 \mathrm{~nm})$ than $0.15(10-24 \mathrm{~nm})$ and 0.1 $\mathrm{mg} / \mathrm{mL}$.

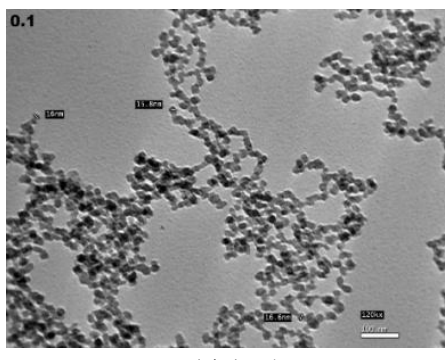

$14-16.5 \mathrm{~nm}$

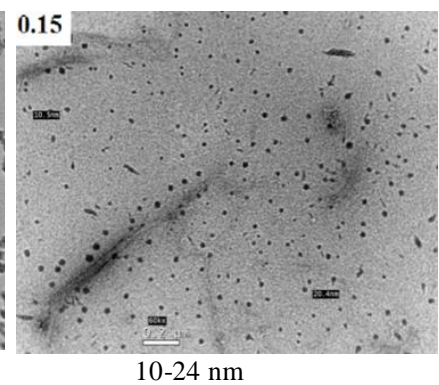

$10-24 \mathrm{~nm}$

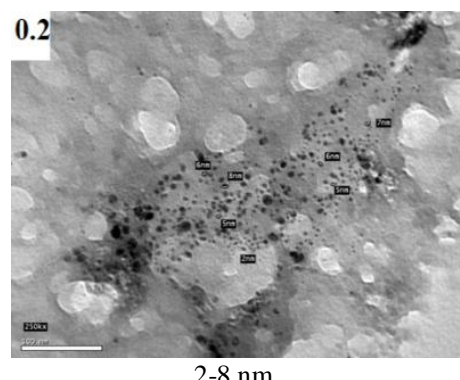

Fig. 2: TEM image of nano chitosan prepared at different concentration of chitosan and its nano size range.

\section{Effect of concentration of sodium tri poly phosphate}

The effect of concentration of sodium tri poly phosphate $(0.05, \quad 0.1, \quad 0.15) \mathrm{g} / \mathrm{ml}$ was studied at constant other parameters:concentration of chitosan at (0.2) $\mathrm{g} / \mathrm{l}$, at $\mathrm{pH}(5.5)$, sonication time 45 minutes at room temperature. Sodium tri poly phosphate (TPP) a major ingredient for cross linking has a pronounced effect on the properties of chitosan dispersion, the concentration of TPP was increased gradually, the solution became opalescent indicating the formation of nanochitosan. It was observed from figure 3 with increase in concentration of TPP, the particle size of chitosan nanoparticle increased, Concentration of TPP above $0.10 \mathrm{~g}$ resulted precipitation. The 
precipitation at excessively higher concentration of TPP may be attributed to the aggregation of chitosan molecules due to excessive cross linking through TPP bridging. As shown at figure 3 , obvious tha tby increasing the chitosan concentration from 0.05 to $0.15 \mathrm{~g} / \mathrm{mL}$ at a constant chitosan concentration $(0.2 \mathrm{~g} / \mathrm{mL})$, the size of chitosan nanoparticles changed from $19 \mathrm{~nm}$ at $(0.05)$ to 12 $\mathrm{nm}$ at $(0.15)$ but the more favorable size $23 \mathrm{~nm}$ at 0.1 of STTP which have a good distribution for a nanoparticle all over the solution.

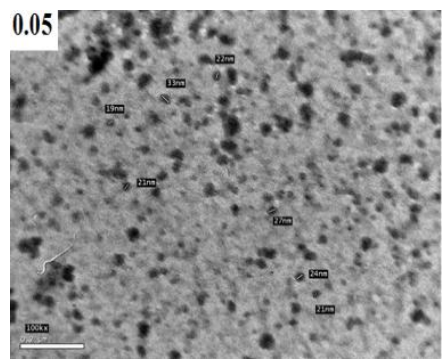

19-32 nm

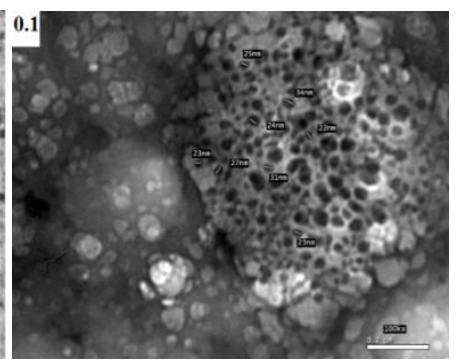

23-34 nm

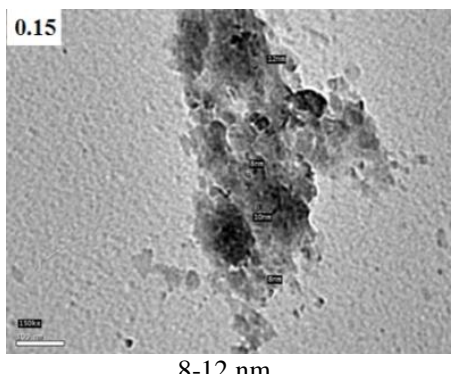

$8-12 \mathrm{~nm}$

Fig. 3: TEM images of nano chitosan prepared at different concentration of TTP and its nano size range.

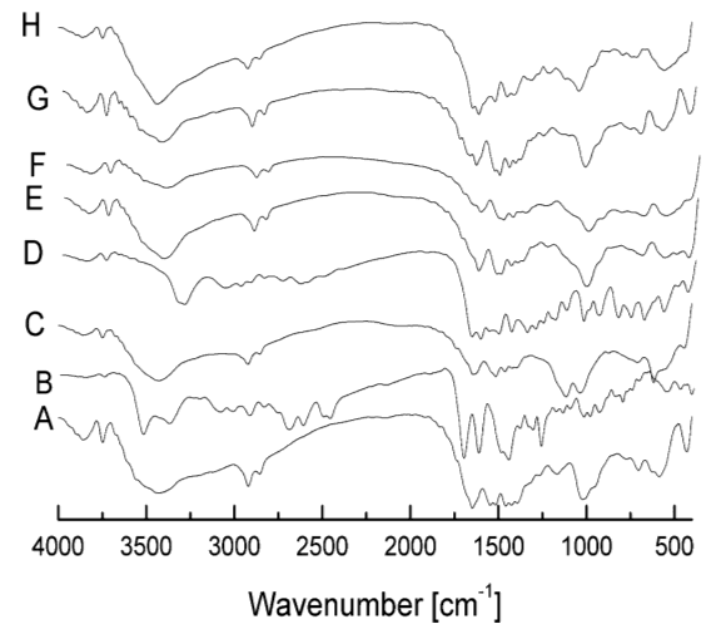

Fig. 4: charts for original and loaded samples A (chitosan), B (ciprofloxacin HCL), C (Gentamycin sulfate) and D (Chlortetracycline HCl), E (CS NPs), F (CS NPs-Cipro), G (CS NPs-Genta) and H (CS NPs-Chloro)

\section{FT-IR Analysis}

Infrared analysis used to detect ciprofloxacin, Gentamycin sulfate and Chlortetracyclinein chitosan nanoparticles.
As expected, chitosan and chitosan nanoparticles shows identical peak absorption as shown in Figure 4 In addition, figure 4 B, C and D shows typical absorption peaks for ciprofloxacin HCL, Gentamycin sulfate and Chlortetracycline $\mathrm{HCl}$ as shown (Agyare et al., 2008; Trapani et al., 2010; Tiyaboonchai, 2013). Chitosan nanoparticles loaded with ciprofloxacin HCL, Gentamycin sulfate and Chlortetracycline $\mathrm{HCl}$ showed different infrared spectra: for ciprofloxacin HCL (Lopez-Gresa et al., 2002), Gentamycin sulfate (Sivakumar et al., 2002; Leypold et al., 2003; Sivakumar and Rao, 2003) and Chlortetracycline $\mathrm{HCl}$ (Friess and Schlapp, 2002)in addition to chitosan nanoparticles itself with proof that these antibiotics successfully loaded on chitosan nanoparticles as shown in figure $1 \mathrm{~F}, \mathrm{G}$ and $\mathrm{H}$.

\section{Antibacterial Activity of chitosan nanoparticles and its loaded antibiotic}

The zntibacterial properties of chitosan nanoparticles and its loaded antibiotic are evaluated against Staphylococcus aureus (S. aureus) as Gram-positive bacteria and Escherichia coli (E. coli) as gram-negative bacteria.

Figure 5 shows that the antibacterial activity of chitosan nanoparticles loaded with ciproflaxin, tetra chlorocycline and gentamycin sulfate are increased with increasing absorbed dose for both gram-positive and gram-negative bacterium. The inhibition zone of chitosan nanoparticles loaded Ciprofloxacin $\mathrm{HCl}$ of $S$. aureus as gram positive bacteria was enhanced from $6.5 \mathrm{~mm}$ to $22 \mathrm{~mm}$ and against $E$. coli as gram negative bacteria from $5.5 \mathrm{~mm}$ to 21 which increase with increasing the concentration of antibiotic as shown in figures 5 and 6.

The inhibition zone of chitosan nanoparticles loaded with tetra chlorocyclin of $S$. aureus as gram positive bacteria was enhanced from $0 \mathrm{~mm}$ to $10 \mathrm{~mm}$ and $0 \mathrm{~mm}$ to $7 \mathrm{~mm}$ for E. coli as gram negative bacteria which increased with increasing the concentration of tetra chlorocycline.

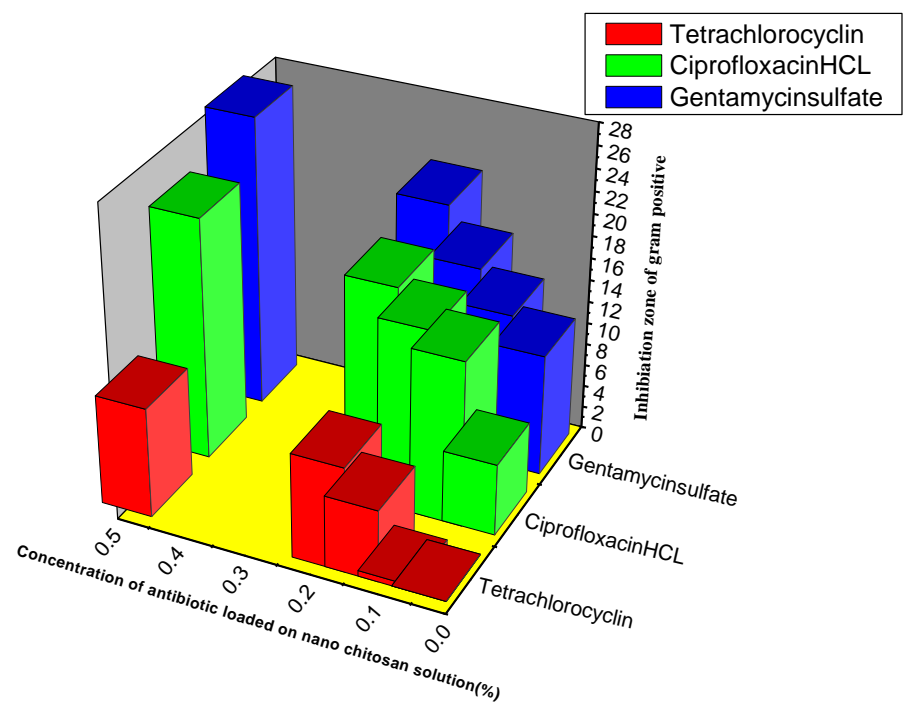

Fig. 5: Effect of Concentration of Antibiotic Loaded on Chitosan Nanoparticles against Inhibition Zone of S. aureus as Gram Positive bacteria. 
As we mentioned before that Chitosan exhibits higher antibacterial activity against Gram-positive bacteria than Gramnegative bacteria, this is due to their different cell walls. But both figures 5 and 6 shows that chitosan nanoparticles shows higher antibacterial towards both Gram-positive and Gram-negative bacteria by similar inhibition zone that is due to chitosan nanoparticles are polycation with high surface charge density which interact with bacteria and tightly absorbed onto the surface of bacterial membrane to disrupt the membrane of both Grampositive bacteria than Gram-negative bacteria, thus kill bacterial cells by the same ratio which overall due to nanoparticle structure (Avadi et al., 2004; Abou-Zeid et al., 2011).

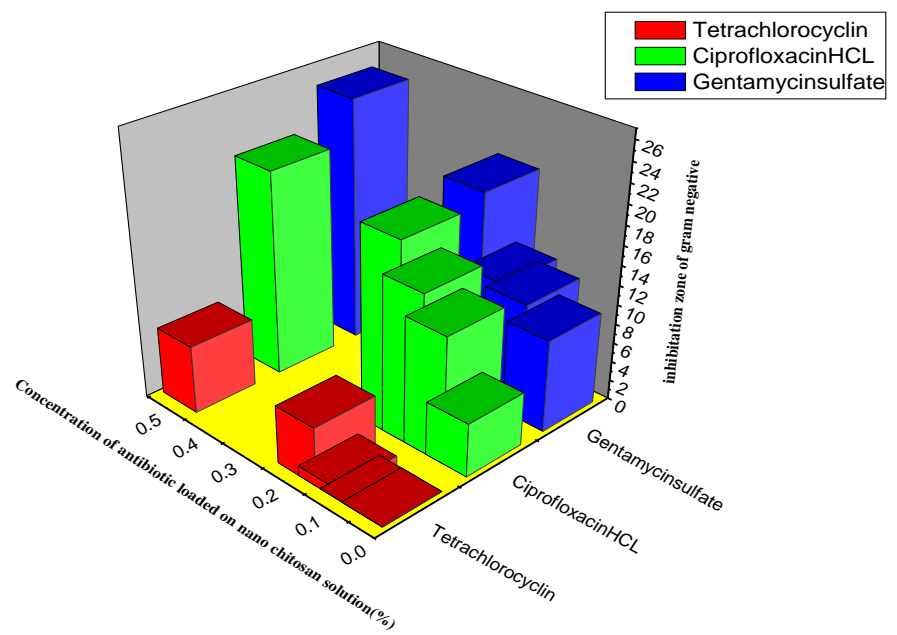

Fig. 6: Effect of Concentration of Antibiotic Loaded on Chitosan Nanoparticles against Inhibition Zone of $E$. coli as gram negative.

Also antibacterial activity of chitosan nanoparticles loaded Gentamycin sulphate increaded from $10 \mathrm{~mm}$ to $26 \mathrm{~mm}$ for $S$. aureus as gram positive bacteria and increased from $8.5 \mathrm{~mm}$ to $24 \mathrm{~mm}$ for E. coli as gram negative bacteria which increased with increasing the concentration of Gentamycin sulphate. Also antibacterial activity increased in the order chitosan nanoparticles loaded with Gentamycin sulphate then ciprofloxacin then tetra cycline at the same concentration which conclude that chitosan nanoparticles loaded Gentamycin sulphate is the best antibacterial material followed by loaded with ciprofloxacin followed by loaded by tetra cycline.

\section{CONCLUSION}

- Chitosan nanoparticles were prepared by using tripoly phosphate and characterized by using FT-IR and TEM.

- $\quad \mathrm{pH}$ and ultrasonication time were kept constant at 5.5 and $45 \mathrm{~min}$. respectively based on previous studies.

- The optimum conditions of preparation of chitosan nanoparticles are: chitosan concentration is $0.2 \mathrm{~g} / \mathrm{ml}$, TPP concentration is $0.1 \mathrm{~g} / \mathrm{ml}$, ultrasonication time is $45 \mathrm{~min}$. and $\mathrm{pH}$ is 5.5 .

- Chitosan nanoparticles were loaded with selected antibiotics (ciprofloxacin HCL, Chlortetracycline hydrochloride and Gentamycin sulfate) to magnify their benefits in biomedical applications.

- Antibacterial activity of chitosan nanoparticles loaded with antibiotics increase with increasing the antibiotic concentration.

- Chitosan nanoparticles exhibits higher antibacterial activity against Gram-positive bacteria than Gram-negative bacteria.

- Order of inhibition for three antbiotics are: Gentamycin sulfate $>$ ciprofloxacin HCL > Chlortetracycline hydrochloride

\section{ACKNOWLEDGEMENT}

The authors gratefully acknowledges National Research Centre, for financial support and for facilities provided through project ID: 10050309.

\section{REFERENCE}

Abdel-Fattah WI, Sallam ASM, Attawa N, Salama E, Maghraby AM,Ali GW. Functionality, antibacterial efficiency and biocompatibility of nanosilver/chitosan/silk/phosphate scaffolds 1. Synthesis and optimization of nanosilver/chitosan matrices through gamma rays irradiation and their antibacterial activity. Materials Research Express, 2012; 1 (3): 035-024.

Abou-Zeid N, Waly A, Kandile N, Rushdy A, El-Sheikh M, Ibrahim H. Preparation, characterization and antibacterial properties of cyanoethylchitosan/cellulose acetate polymer blended films. Carbohydrate Polymers, 2011; 84 (1): 223-230.

Agyare EK, Curran GL, Ramakrishnan M, Caroline CY, Poduslo JF, Kandimalla KK. Development of a smart nano-vehicle to target cerebrovascular amyloid deposits and brain parenchymal plaques observed in Alzheimer's disease and cerebral amyloid angiopathy. Pharmaceutical Research, 2008; 25 (11): 2674-2684.

Avadi M, Sadeghi A, Tahzibi A, Bayati K, Pouladzadeh M, Zohuriaan-Mehr M, Rafiee-Tehrani M. Diethylmethyl chitosan as an antimicrobial agent: Synthesis, characterization and antibacterial effects. European Polymer Journal, 2004; 40 (7): 1355-1361.

Benhabiles M, Salah R, Lounici H, Drouiche N, Goosen M,Mameri N. Antibacterial activity of chitin, chitosan and its oligomers prepared from shrimp shell waste. Food hydrocolloids, 2012; 29 (1): 4856.

Chattopadhyay D, Inamdar M. Improvement in properties of cotton fabric through synthesized nano-chitosan application. Indian J Fibre Textil Res, 2013; 38 14-21.

Chopra AK, Marwaha RK, Kaushik D, Dureja H. Box-Behnken Designed Fluconazole Loaded Chitosan Nanoparticles for Ocular Delivery. Pharmaceutics \& Drug Delivery Research, 2014;

Chopra I, Hodgson J, Metcalf B, Poste G. The search for antimicrobial agents effective against bacteria resistant to multiple antibiotics. Antimicrobial agents and chemotherapy, 1997; 41 (3): 497.

Cruz-Romero M, Murphy T, Morris M, Cummins E, Kerry J. Antimicrobial activity of chitosan, organic acids and nano-sized solubilisates for potential use in smart antimicrobially-active packaging for potential food applications. Food Control, 2013; 34 (2): 393-397.

Csaba N, Alonso M. Biodegradable polymer nanoparticles as protein delivery systems: Original research articles: Design of biodegradable particles for protein delivery (2002), Chitosan nanoparticles as delivery systems for doxorubicin (2001); design of microencapsulated chitosan microspheres for colonic drug delivery (1998). Journal of controlled release, 2014; 190: 53-4. 
Dash M, Chiellini F, Ottenbrite RM, Chiellini E. Chitosan-A versatile semi-synthetic polymer in biomedical applications. Progress in polymer science, 2011; 36 (8): 981-1014.

Del Guidice G, Baudner B, Mucosal vaccines with chitosan adjuvant and meningococcal antigens, 2015, Google Patents.

Du W-L, Niu S-S, Xu Y-L, Xu Z-R, Fan C-L. Antibacterial activity of chitosan tripolyphosphate nanoparticles loaded with various metal ions. Carbohydrate Polymers, 2009; 75 (3): 385-389.

El-Sherbiny IM,El-Baz NM. A Review on Bionanocomposites Based on Chitosan and Its Derivatives for Biomedical Applications. Ecofriendly Polymer Nanocomposites: Chemistry and Applications, 2015; 74 173.

Friess W, Schlapp M. Release mechanisms from gentamicin loaded poly (lactic-co-glycolic acid)(PLGA) microparticles. Journal of pharmaceutical sciences, 2002; 91 (3): 845-855.

Garrait G, Beyssac E, Subirade M. Development of a novel drug delivery system: chitosan nanoparticles entrapped in alginate microparticles. Journal of microencapsulation, 2014; 31 (4): 363-372.

Jain D, Banerjee R. Comparison of ciprofloxacin hydrochlorideloaded protein, lipid, and chitosan nanoparticles for drug delivery. Journal of Biomedical Materials Research Part B: Applied Biomaterials, 2008; 86 (1): 105-112.

Jia Z, Xu W. Synthesis and antibacterial activities of quaternary ammonium salt of chitosan. Carbohydrate research, 2001; 333 (1): 1-6.

Jimtaisong A, Saewan N. Utilization of carboxymethyl chitosan in cosmetics. International journal of cosmetic science, 2014; 36 (1): 12 21.

Kim TH, Park IK, Nah JW, Choi YJ, Cho CS. Galactosylated chitosan/DNA nanoparticles prepared using water-soluble chitosan as a gene carrier. Biomaterials, 2004; 25 (17): 3783-3792.

Lahmer RA, Williams AP, Townsend S, Baker S, Jones DL. Antibacterial action of chitosan-arginine against Escherichia coli O157 in chicken juice. Food Control, 2012; 26 (1): 206-211.

Leypold C, Reiher M, Brehm G, Schmitt M, Schneider S, Matousek P, Towrie M. Tetracycline and derivatives - assignment of IR and Raman spectra via DFT calculations. Physical Chemistry Chemical Physics, 2003; 5 (6): 1149-1157.

Li Z, Zhuang XP, Liu XF, Guan YL, De Yao K. Study on antibacterial O-carboxymethylated chitosan/cellulose blend film from LiCl/N, N-dimethylacetamide solution. Polymer, 2002; 43 (4): 15411547.

Limam Z, Selmi S, Sadok S, El Abed A. Extraction and characterization of chitin and chitosan from crustacean by-products: Biological and physicochemical properties. African journal of biotechnology, 2013; 10 (4): 640-647.

Liu L, Dong X, Zhu D, Song L, Zhang H, Leng XG. TATLHRH conjugated low molecular weight chitosan as a gene carrier specific for hepatocellular carcinoma cells. International journal of nanomedicine, 2014; 92879.

Lopez-Gresa M, Ortiz R, Perello L, Latorre J, Liu-Gonzalez M, Garcia-Granda S, Perez-Priede M, Canton E. Interactions of metal ions with two quinolone antimicrobial agents (cinoxacin and ciprofloxacin): Spectroscopic and X-ray structural characterization. Antibacterial studies. Journal of inorganic biochemistry, 2002; 92 (1): 65-74.

Lu E, Franzblau S, Onyuksel H, Popescu C. Preparation of aminoglycoside-loaded chitosan nanoparticles using dextran sulphate as a counterion. Journal of microencapsulation, 2009; 26 (4): 346-354.

Lu H, Dai Y, Lv L, Zhao H. Chitosan-graft-polyethylenimine /DNA nanoparticles as novel non-viral gene delivery vectors targeting osteoarthritis. 2014;
Lu Y, Cheng D, Lu S, Huang F, Li G. Preparation of quaternary ammonium salt of chitosan nanoparticles and their textile properties on Antheraea pernyi silk modification. Textile Research Journal, 2014; 84 (19): 2115-2124.

Nascimento AV, Singh A, Bousbaa H, Ferreira D, Sarmento B, Amiji MM. Mad2 checkpoint gene silencing using epidermal growth factor receptor-targeted chitosan nanoparticles in non-small cell lung cancer model. Molecular pharmaceutics, 2014; 11 (10): 3515-3527.

No HK, Park NY, Lee SH, Meyers SP. Antibacterial activity of chitosans and chitosan oligomers with different molecular weights. International journal of food microbiology, 2002; 74 (1): 65-72.

Qi L, Xu Z, Jiang X, Hu C, Zou X. Preparation and antibacterial activity of chitosan nanoparticles. Carbohydrate research, 2004; 339 (16): 2693-2700.

Ragelle H, Riva R, Vandermeulen G, Naeye B, Pourcelle V, Le Duff CS, D'Haese C, Nysten B, Braeckmans K, De Smedt SC. Chitosan nanoparticles for siRNA delivery: optimizing formulation to increase stability and efficiency. Journal of Controlled Release, 2014; 176 54-63.

Sawaengsak C, Mori Y, Yamanishi K, Mitrevej A, Sinchaipanid N. Chitosan nanoparticle encapsulated hemagglutinin-split influenza virus mucosal vaccine. AAPS PharmSciTech, 2014; 15 (2): 317-325.

Sivakumar M, Manjubala I, Rao KP. Preparation, characterization and in-vitro release of gentamicin from coralline hydroxyapatite-chitosan composite microspheres. Carbohydrate Polymers, 2002; 49 (3): 281-288.

Sivakumar M, Rao KP. Preparation, characterization, and in vitro release of gentamicin from coralline hydroxyapatite-alginate composite microspheres. Journal of Biomedical Materials Research Part A, $2003 ; 65$ (2): 222-228.

Taubes G. The bacteria fight back. Science, 2008; 321 356-61.

Tiyaboonchai W. Chitosan nanoparticles: a promising system for drug delivery. Naresuan University Journal: Science and Technology, 11 (3): 51-66.

Trapani A, Lopedota A, Franco M, Cioffi N, Ieva E, GarciaFuentes M,Alonso MJ. A comparative study of chitosan and chitosan/cyclodextrin nanoparticles as potential carriers for the oral delivery of small peptides. European Journal of Pharmaceutics and Biopharmaceutics, 2010; 75 (1): 26-32.

Van der Lubben I, Verhoef J, Borchard G, Junginger $H$. Chitosan for mucosal vaccination. Advanced Drug Delivery Reviews, 2001; 52 (2): 139-144.

Walsh C. 2003. Antibiotics. American Society of Microbiology.

Walsh C. Where will new antibiotics come from? Nature Reviews Microbiology, 2003; 1 (1): 65-70.

$\mathrm{Xu} \mathrm{Y,} \mathrm{Du} \mathrm{Y.} \mathrm{Effect} \mathrm{of} \mathrm{molecular} \mathrm{structure} \mathrm{of} \mathrm{chitosan} \mathrm{on}$ protein delivery properties of chitosan nanoparticles. International Journal of Pharmaceutics, 2003; 250 (1): 215-226.

Zaki NM, Hafez MM. Enhanced antibacterial effect of ceftriaxone sodium-loaded chitosan nanoparticles against intracellular Salmonella typhimurium. AAPS Pharm Sci Tech, 2012; 13 (2): 411-421.

\section{How to cite this article:}

Hassan M. Ibrahim, Manal K. El-Bisi, Ghada M. Taha, Ekhlas A. El-Alfy. Chitosan nanoparticles loaded antibiotics as Drug Delivery bio material. J App Pharm Sci, 2015; 5 (10): 085-090. 